\title{
The Main Features and the Key Challenges of the Education System in Taiwan
}

\author{
Chiu-Kuei Chang Chien ${ }^{1}$, Lung-Chi Lin $^{2} \&$ Chun-Fu Chen ${ }^{3}$ \\ ${ }^{1}$ Language Teaching Center, WuFeng University, Chaiyi, Taiwan \\ ${ }^{2}$ Department of Applied Foreign Languages, Kao Yuan University, Kaohsiung, Taiwan \\ ${ }^{3}$ Department of Applied English, WuFeng University, Chaiyi, Taiwan \\ Correspondence: Chiu-Kuei Chang Chien, Language Teaching Center, WuFeng University, (Yun Shui Ju Room \\ 330) 55, Sec 1, Nanhua Rd., Dalin Township, Chiayi County 62249, Taiwan. Tel: 886-226-7125. E-mail: \\ sandra0914@livemail.tw
}

Received: August 19, $2013 \quad$ Accepted: November 4, 2013 Online Published: November 22, 2013
doi:10.5539/hes.v3n6p1
URL: http://dx.doi.org/10.5539/hes.v3n6p1

\begin{abstract}
Taiwan has undergone radical innovation of its educational system in the wake of political liberalization and democratization, with a request for a change in the idea which diverts from 'de-centralization' to 'individualization'. The reforms have led to two main features of pluralism and generalization of education in our current education system with a view to more equal and plural opportunities of education for students in Taiwan. Nevertheless, a number of reform tasks have been done in haste without discretion and have developed various problems with some deriving from the inherent educational system and some from the reform tasks themselves. The paper discusses three major educational reform concerns and the problems associated with these concerns including multilingual learning in elementary schools, overexpansion of higher education institutions and 12-year compulsory education.
\end{abstract}

Keywords: Taiwan, education reform, multilingual learning, overexpansion, higher education institution, 12-year compulsory education

\section{Introduction}

\subsection{Background}

For the past few years, Taiwan has undergone radical innovation of its educational system in the wake of political liberalization and democratization. After the lift of martial law in 1987 (Law, 1995; Tsai \& Shavit, 2003), a time marking an end of the authoritarian dictatorship of the Kuomintang government, a trend of thought to seek autonomy and liberal expression lurked in society as well as on university campuses (Tu, 2007). In addition, under the influence of various social movements, educational reforms were being carried out in western countries $(\mathrm{Tu}$, 2005; Yang, 2001), coupled with a hope to improve the educational system and cultivate more talented citizens. In the meantime, increased democracy on university campuses, student autonomy and academic liberty were requested. In the beginning of 1990s, the public urged a call for educational examination and regulation with a view to enhance national education standards and reinforce international competitiveness, as is highlighted of education reforms worldwide (Berman, 1996; Yang, 2000).

A full-blown educational reform was initiated after the movement of "410 Demonstration for Education Reform" on 10 April, 1994 (Tu, 2007), a petition mainly to withdraw excessive control and duress inflicted upon education by the government. The aims were to modernize the educational system, draft an underlying educational law, establish more high schools and universities, and request for a change of the idea of 'de-centralization' to 'individualization'. As Tu (2007, p. 12) puts it, 'The previous top-down linear government system, from central to local, from government agencies to individual schools, needed to be replaced; instead, teachers and schools should be able to form the mainstay of education and take charge of education matters.' In response to the claims made by the social groups, an Educational Reform Committee was established by the Executive Yuan in July 1994 (Chen, 2002), acting as an agent between the government (Ministry of Education) and the social groups. 


\subsection{Main Features of the Education System in Taiwan}

The reforms of the education policies over the past few years have formed two main features that characterize the current education system of Taiwan; one is 'pluralism' or alleged 'loosening of restriction' (Wang, 2005), and the other is generalization of education. The reform tasks under the framework of pluralism include execution of a multi-channel school admission system for senior high schools and vocational schools, universities, and technical schools for diverse enrollment and provision of pluralistic teacher training channels at numerous universities and colleges. The pluralism also features alternative choice of multiple editions of textbooks for the integrated Grade 1-9 curriculum replacing the traditional way of using designated textbooks by the Ministry of Education (MOE), multilingual learning by adding English and vernacular languages to the elementary school curriculum and vernacular languages to the junior high school curriculum. Other features related to pluralism include providing diversified types of educational programs for secondary education such as bilateral high schools combining vocational and academic tracks, implementing and improving vocational and practical skills curricula for junior high and vocational high school students with lower academic achievement and offering more elective courses related to specific learning areas (MOE, 2009).

The reform tasks under the framework of generalization include the planning of 12-year compulsory education mainly to advance equal learning opportunities and shorten the gap between public schools and private schools and urban schools and rural schools in terms of student enrollment and provision of teaching and learning resources. Other features include providing supplementary education purporting to increase the countrymen opportunities to receive education, which covers three types including basic education, advanced education and short-term supplementary education. Special classes are also offered to the mentally- and physically-disabled, and which are provided by regular education institutions including at most six years' study at preschools and elementary schools, three years' study at junior high schools and senior high schools and vocational schools respectively (MOE, 2009). Social education is also offered with aims to encourage lifelong learning, foster cultural activities, strengthen public social education function, and provide female immigrants adult educational classes. Other than the above, offering five-year olds free tuition, providing multicultural education, assuring equality in education for both males and females, bettering auxiliary digital education and setting up community education networks are all signs of generalization of education in Taiwan (MOE, 2009).

Education reforms in Taiwan originated from numerous social movements, and the principles on which the reformers based were the public's appeal of equitable educational opportunities and fair distribution of teaching and learning resources. The efforts the government has exerted for our education have indeed brought about changes of pluralism and generalization of the education system. These have led to dramatic effects by means of allowing diverse enrollment, offering plural teaching and learning channels, having more courses to choose from, improving skills and education, and implementing more consolidated and coherent curricula. The results of the reforms might make us feel satisfied, at least in principle, for there are more channels for our citizens to receive education.

Yet, the educational reform was considered a task of urgency by the new Democratic Development Party (DPP) government in the late 1990s (Chen, 2002; Tu, 2007; Yang, 2001), with numerous tasks carried out in haste without discretion by the reformers. Many problems have been revealed, with some being inherent in the conventional educational system and some derivative from the reform tasks themselves. It is argued that many of the policies do not accord with their original intention and lack deliberate evaluation. A muddled phenomenon has existed in our educational reforms as Wang $(2005$, p. 2) contends: "While pursuing the pluralism, we seem to have ignored the continuity in logics and effected the reformation without cautious consideration."

The following section addresses the three major education reform concerns and the problems accompanying these concerns in current educational system in Taiwan including multilingual learning in elementary schools, overexpansion of higher educational institutions and 12-year compulsory education.

\section{The Three Important Educational Reform Concerns and the Problems}

\subsection{Multilingual Learning in Elementary Schools}

To promote linguistic pluralism for integration in Taiwan, a multi-lingual, multi-ethnic country (Huang, 1993), two language policies were officially implemented in 2001. One was advancing English learning from Grade 5 in elementary schools (starting from Grade 3 in 2005 to match the Grades 1-9 Curriculum Guidelines revised by the $\mathrm{MOE}$ ), the other being learning of vernaculars at elementary and junior high schools. Other purposes of the language policies are to preserve ethnic languages in the light of a phenomenon of decreasing use of indigenous languages among younger indigenous generation (Huang, 2000), who are virtually semi-speakers (i.e., understand the language but do not use it) as claimed by Schmidt (1990); and to enhance communicative competence in 
response to the trend of globalization. The two language policies have made Taiwanese elementary students and some of junior high school students, for whom the vernacular language course is provided as an elective, become multilingual learners (Chen, 2006; Law, 2002). Here the elementary language education is what the reform is mainly concerned about, particularly for first-graders, who are required to study Mandarin Chinese and one vernacular selected from Minnanese also called Taiwanese, Hakka, and aboriginal languages. Some students are also required to take English course because some schools advance English education from Grade 1.

In fact, since the above language learning policies were promulgated, a number of Taiwanese citizens have contended against the mutual interference of simultaneous learning of 'so' many languages, especially for first graders having just started their formal education and whose native language literacy (hereafter referring to Mandarin Chinese) has not yet reached maturity (E, 2003). Although many researchers such as Lenneberg (1967), Bickerton (1981) and Brown (2000) have advocated the critical period (CPH), a very decisive point when acquisition of a second language occurs, to encourage earlier cultivation of language knowledge, research has also found evidence of cross-linguistic interference derived from contrastive analysis in studies concerning multilingual learning.

For instance, a study conducted by Tai (2000) has found evidence of interference of Southern Min in some students' pronunciation of English, who uttered $/ \mathfrak{x} /$ as $/ \varepsilon /, / \mathrm{v} /$ as $/ \mathrm{p} /, / \mathrm{b} /, / \mathrm{f}(\mathrm{u}) /, / \mathrm{m} /$ or $/ \mathrm{h}(\mathrm{u}) /$, and $/ \mathrm{z} /$ as $/ \mathrm{ts} /, / \mathrm{s} /$ or $/ \mathrm{l} /$. Erroneous production of L1 influenced by L2 was found in Lin's (2002) study at a elementary school in Xinzhu in northern Taiwan concerning interference of English phonetic symbols in learning POJ (Pej-oe-ji), Minnanese characters, using Roman spelling system. Six collocations of mispronunciation were identified such as confusion of 'p' and 'b', 't' and 'd', 'k' and ' $\mathrm{g}$ ', 'ph' and 'p', 'th' and 't', and 'kh' and ' $\mathrm{k}$ '. Learning of Mandarin Chinese and vernaculars also interfered mutually according to Kao's (2001) interviews with a group of elementary school teachers referring to the problems of first-graders' confusion in learning Chinese auxiliary phonetic script-Zhu-Yin-Fu-Hao (つ文ワモ), with the Roman spelling symbols of Minnanese POJ.

Given whether cross-linguistic influence manifests itself as a 'positive transfer' or 'negative transfer' (Romaine, 1995), a certain degree of interference was readily perceived in some classroom language learning, especially for those beginning learners who have not developed their L1, yet are required to construct the knowledge of another two languages. Moreover, in terms of psychological effect of multilingual learning, it is argued that learners' burden is not seen as a priority when the education authorities are trying to create an ideal multicultural society.

In addition to the problem concerning multilingual learning, a paradox underlying the advocacy of multilingual education is also observed, with the government laying more stress on English education than vernacular language education (Chen, 2006). As can be discerned, the purpose to include vernacular languages in the elementary curriculum as a formal subject is to preserve the dialects of smaller ethnic groups, promoting each dialect for an equal status in our society. However, a phenomenon of schools not attaching much weight to instruction of native languages is identified (Chen, 2004; Chen, 2006; Qian, 1996; Yang, 2002). As Chen (2006, p. 323) contended, English education policy "was more systematically and thoroughly planned by the central government, and more vigorously implemented by all parties concerned" than was the local language education policy.

Moreover, more teaching hours are allocated to English learning, roughly one to six hours per week (Chen, 2006). Taking the elementary schools in New Taipei City for example, to build up a fundamental knowledge ability in English reading and writing which is perceived as a worldwide 'core competency', three different types of English-related classes were added to the fifth and sixth graders' English curricula in the New Taipei City's elementary schools in 2010 and this has made the students in elementary schools have longer English learning hours than those in junior high schools in the New Taipei City (Wu, 2011). In contrast, most elementary schools chose to meet the minimum requirement of one hour per week for vernacular language instruction, implying less emphasis on vernacular language education (Chen, 2004; Chen, 2006; Qian, 1996; Yang, 2002).

Likewise, more qualified teachers are recruited for English instruction; however, much fewer competent native language teachers are available to teach vernacular languages, a barrier commonly observed in multi-language classrooms (Klaus, 2003). As usual, substitute or part-time teachers and homeroom teachers dominate vernacular language teaching across the country, and only few qualified teachers teach full time (Chen, 2004; Chen, 2006), demonstrating less enthusiasm devoted to vernacular language education of schools (Chen, 2006). Moreover, a wider selection of pedagogically sound, well-designed textbooks and facilities such as computer software are available for English teaching and learning; contrarily, fewer textbooks and limited facilities are offered to local language education. Also, a more inclusive and systematic assessment including formative and summative measures is administered to learners of English but not to those of vernacular languages (Chen, 2006). Drawn from the above revelations, it is argued that one may ascribe such contrasting phenomena between English 
instruction and the instruction of vernacular languages to a lack of a punctilious scheme and hasty implementation of dialect learning secured by the concerned authorities.

As far as the instruction of vernacular languages is concerned, an unequal distribution of vernacular language instruction is also observed. Figure 1 shows an ascendancy of vernacular Minnanese language learning which accounts for $80 \%$ in year 2005. Contrarily, it shows a smaller number of classes learning Hakka and aboriginal languages (MOE, 2009).

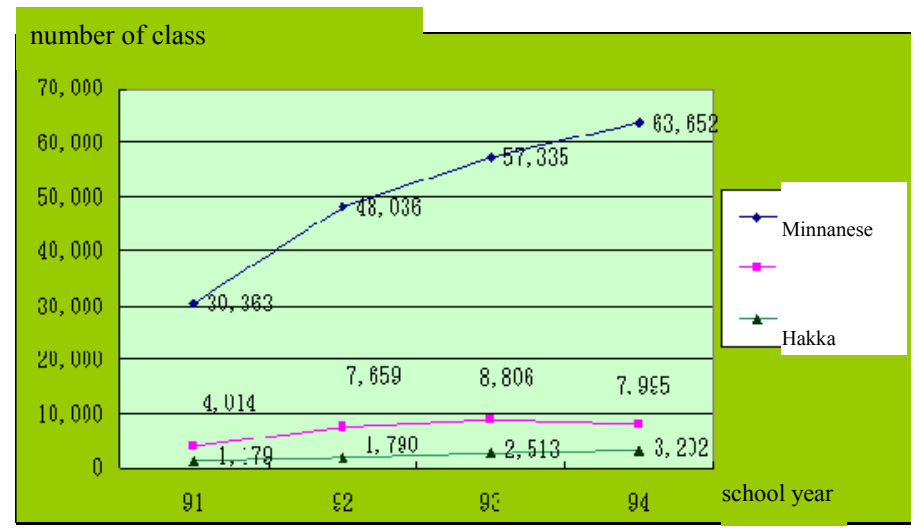

Figure 1. Distribution of vernacular languages learning in elementary schools and junior high schools in Taiwan

While it is true that a great many people in Taiwan can speak Minnanese (around 73\%) (Chen, 2006) and there are more Minnanese classes offered in schools, it is argued that the society as a whole has taken a more negative attitude toward less spoken dialects such as Hakka and aboriginal languages, which may explain the phenomenon of such differentiation in terms of the selection of teaching and learning of vernacular languages. Moreover, although the selection of local languages made by each school is subject to the ethnic origin of the majority of students and the availability of teachers, Hakka and aboriginal languages, long perceived as less prestigious and instrumental in the society, tend to be avoided by schools and teachers (Jiang, 1995; Law, 2002; Liu, 1998). Still yet the teaching of aboriginal languages is even not supported by aboriginal families and the respective communities (Law, 2002; Yang, 2002).

Hence, a dominant Minnanese language instruction might lead to a condition where "a movement intended to save a minority language may turn out to be a new form of oppression that threatens other minority languages" (Chen, 2006, p. 329; Hsiau, 1997, p. 313). In addition, solid evidence also supports the argument that teachers' beliefs and attitudes have a great effect on their perceptions and behaviors in language teaching and learning classrooms (Clark \& Peterson, 1986; Kagan, 1992; Villegas, 1992). Therefore, it is argued that teachers' lukewarm attitude might be a decisive factor hindering the implementation of the vernacular language instruction in elementary schools.

Another problem relating to the indigenous language education is the absence of a well-developed writing system (Chen, 2006). Unlike Mandarin Chinese or English, vernacular languages only have spoken forms without corresponding written characters, making it necessary to develop spelling systems for local languages teaching and learning. Though different versions of spelling systems have been developed, many people have found them quite confusing, and different schools tend to use different spelling systems. For example, some schools use POJ, others use Taiwanese Language Phonetic Alphabet, and still others use Tongyong Pinyin (general transliteration). Consequently, when a learner goes to a school using a different spelling system, unsurprisingly, a condition of higgledy-piggledy or a discontinuity of learning may be expected. In addition, while teaching vernacular languages, many teachers are not apt to highlight learners' literacy abilities owing to their unfamiliarity with the writing systems in the textbooks and a stereotyped conviction of the function of local languages for communicative purposes only (Chen, 2006). Therefore, it is questionable concerning the efficacy of local language literacy training under such hasty execution which lacks overall planning regarding the formulation of a standardized spelling system.

\subsection{Overexpansion of Higher Education Institutions}

Following the removal of martial laws, the higher education system in Taiwan has been 
"depoliticizing"-liberating itself from the interference of the ruling party (Law, 1995). Moreover, the deregulation of the educational policies following the appeals of the League 410 has contributed to a massive expansion of higher education institutions over the past fifteen years (see Table 1) along with an upgrade of a number of post-secondary institutions, inclusive of two-year and five-year junior colleges, institutes of technology, universities of technology and general universities. Additionally, more departments have been added to attract more students owing to a keen competition among higher education institutions. Such tremendous expansion has elevated the average level of education of Taiwanese citizens (Lin, 2007); moreover, it has also transformed Taiwan's higher education from traditional elite education with a ratio of enrollment lower than $15 \%$ to general education (Throw, 1974). In 2006, a gross enrollment rate of 18- to 21-year-old students-those receiving education at colleges and universities with the exception of the first 3 years of education at five-year junior colleges, graduate schools and continuing schools-is estimated at $82.02 \%$, in contrast to half that amount at $40.90 \%$ in 1996 and four times less at $21.58 \%$ in 1986 (Directorate-General of Budget, Accounting, and Statistics, Executive Yuan, Taiwan, 2007). Over the past five years, the enrollment rate for the College Entrance Examination in specified subject has reached over 90 percent and the University's Multiple Entrance Exam has reached over 70 percent enrollment (MOE, Department of Statistics, 2012).

Without doubt, the intention behind the policy was evident partly to increase the number of enrollment of college and university students and decrease intense competition among students jostling to enter higher education institutions, and partly to, hopefully, cultivate very large competent graduate cohorts. However, there seems to be dissonance between what the concerned authorities had expected and what is currently happening in higher education institutions. Ironically, low quality education is perceived (Huang, 2003; Wang, 2003), with less qualified college students and high unemployment rates among college graduates observed. The overexpansion has led to an unobstructed entry to higher education institutions of senior high graduates formerly having little access to higher education institutions (Mok, 2000). In fact, except for some colleges/universities on the top rankings, almost every secondary school graduate is eligible to enter into colleges or universities, both competent and less competent included.

Table 1. Number of schools of higher education

\begin{tabular}{lcccc}
\hline & Junior college & College & University & Total \\
\hline 1950 & 3 & 3 & 1 & 7 \\
1960 & 12 & 8 & 7 & 27 \\
1970 & 70 & 13 & 9 & 92 \\
1980 & 77 & 11 & 16 & 104 \\
1990 & 75 & 25 & 21 & 121 \\
2000 & 23 & 74 & 53 & 150 \\
2005 & 17 & 56 & 89 & 162 \\
2010 & 15 & 36 & 112 & 163 \\
2012 & 14 & 28 & 120 & 162 \\
\hline
\end{tabular}

Many factors contribute to this degradation of higher education institutions. One factor is that many schools failed to readjust curricula after the overexpansion of higher education institutions (Hsu, 2004). It is fair to say that the overexpansion of higher education institutions has increased the opportunities of the younger generation to gain a college degree and increase the number of students in Taiwan receiving higher education. However, an observed phenomenon accompanying the large enrollment of secondary graduates is that heterogeneous classes prevail in colleges/universities with more proficient students sitting in the same classroom with less proficient ones. As with the case of the UK, a less homogenous student population has fueled such expansion of higher education (Nixon, 1996). As a result, it is often the case that competent learners find that an offered lesson is too easy for them, while less competent learners feel it hard to follow it. Clearly an emphasis should be pressingly placed on the need for pedagogical and curriculum changes to cater for the needs of students with mixed abilities (Nixon, 1996). As Parry (1995, p. 125) states, the turning away "from an early notion of access based on defined routes and discrete courses to one more centrally concerned with the 'accessibility' of institutions and the suitability and flexibility of their curricula for a diverse student audience". 
Another factor generating the descending quality of higher education institutions is low enrollment of students encountered by numerous colleges and universities, inasmuch as the fertility rate continues to drop in the Taiwanese society (Huang, 2003) (see Table 2, Resource: Ministry of the Interior-Department of Statistics, Taiwan, 2012). According to Liu and Wang (2004), the total fertility rate (TFR) of Taiwanese women being able to bear children has been falling since 1951, though there is an upward tendency due to the effect of dragon year (Freedman, Chang, \& Sun, 1994; Goodkind, 1993; Liu \& Wang, 2004; Sun, Lin, \& Freedman, 1978). In addition, according to Population Reference Bureau's statistics in 2006 (World Population Data Sheet), excluding Hong Kong and Macao, Taiwan and Korea have the lowest total fertility rates (TFR) of 1.1, and a projected population change of -13 of Taiwan from 2006 to 2050 (Note $1 \&$ Note 2). Based on the figures of demographic statistics, it is evident that the government made an insensible decision by allowing the rapid expansion of junior colleges, colleges and universities without critical assessment of the demographics of the country.

The low fertility rate has brought about the enrollment problem of higher education institutions. Due to insufficient student number, institutions tend to adopt permissive management toward students in order to retain students, an abnormal phenomenon that has been observed in higher education institutions in recent years. Moreover, failure in recruiting sufficient students has made institutions allow, or one might say 'direct' instructors to adopt a less strict way toward students or their schoolwork (Epochtimes, June 7, 2007). This has a direct impact, to a greater or lesser degree, on the overall student achievement along with the teaching quality of higher education institutions in Taiwan.

Table 2. Total fertility rate (TFR) for women of child bearing age from 1951 to 2011

\begin{tabular}{|c|c|c|c|c|c|c|c|c|c|}
\hline \multirow{3}{*}{ Year } & \multirow{3}{*}{$\begin{array}{l}\text { General } \\
\text { Fertility } \\
\text { Rate }\end{array}$} & \multicolumn{7}{|c|}{ Age-specific Fertility Rates } & \multirow{3}{*}{$\begin{array}{l}\text {-Total } \\
\text { Fertility } \\
\text { Rate }\end{array}$} \\
\hline & & & & & $30-34$ & & & & \\
\hline & & Years & Years & Years & Years & Years & Years & Years & \\
\hline 1951 & 211 & 68 & 267 & 350 & 311 & 226 & 132 & 34 & 7,040 \\
\hline 1956 & 196 & 51 & 264 & 340 & 296 & 222 & 105 & 23 & 6,505 \\
\hline 1961 & 177 & 45 & 248 & 342 & 245 & 156 & 71 & 10 & 5,585 \\
\hline 1966 & 149 & 40 & 274 & 326 & 188 & 91 & 38 & 6 & 4,815 \\
\hline 1971 & 112 & 36 & 224 & 277 & 134 & 51 & 16 & 3 & 3,705 \\
\hline 1976 & 105 & 38 & 213 & 241 & 88 & 28 & 8 & 1 & 3,085 \\
\hline 1981 & 89 & 31 & 176 & 197 & 69 & 14 & 3 & 1 & 2,455 \\
\hline 1982 & 85 & 29 & 166 & 186 & 66 & 14 & 3 & 0 & 2,320 \\
\hline 1983 & 79 & 26 & 154 & 174 & 63 & 14 & 3 & 0 & 2,170 \\
\hline 1984 & 75 & 23 & 144 & 169 & 60 & 13 & 2 & 0 & 2,055 \\
\hline 1985 & 68 & 19 & 129 & 158 & 56 & 12 & 2 & 0 & 1,880 \\
\hline 1986 & 60 & 18 & 112 & 140 & 52 & 12 & 2 & 0 & 1,680 \\
\hline 1987 & 60 & 16 & 109 & 147 & 54 & 12 & 2 & 0 & 1,700 \\
\hline 1988 & 64 & 16 & 111 & 164 & 64 & 14 & 2 & 0 & 1,855 \\
\hline 1989 & 58 & 16 & 98 & 145 & 61 & 14 & 2 & 0 & 1,680 \\
\hline 1990 & 62 & 17 & 100 & 159 & 69 & 15 & 2 & 0 & 1,810 \\
\hline 1991 & 58 & 17 & 92 & 149 & 68 & 16 & 2 & 0 & 1,720 \\
\hline 1992 & 57 & 17 & 91 & 148 & 72 & 16 & 2 & 0 & 1,730 \\
\hline 1993 & 57 & 17 & 91 & 149 & 75 & 18 & 2 & 0 & 1,760 \\
\hline 1994 & 55 & 17 & 87 & 148 & 79 & 18 & 2 & 0 & 1,755 \\
\hline 1995 & 55 & 17 & 86 & 148 & 82 & 20 & 2 & 0 & 1,775 \\
\hline 1996 & 54 & 17 & 83 & 145 & 84 & 21 & 2 & 0 & 1,760 \\
\hline
\end{tabular}




\begin{tabular}{llllllllll}
1997 & 53 & 15 & 80 & 147 & 87 & 22 & 3 & 0 & 1,770 \\
1998 & 43 & 14 & 66 & 116 & 73 & 21 & 3 & 0 & 1,465 \\
1999 & 45 & 13 & 66 & 126 & 82 & 21 & 3 & 0 & 1,555 \\
2000 & 48 & 14 & 72 & 133 & 90 & 24 & 3 & 0 & 1,680 \\
2001 & 41 & 13 & 62 & 106 & 75 & 21 & 3 & 0 & 1,400 \\
2002 & 39 & 13 & 57 & 102 & 73 & 20 & 3 & 0 & 1,340 \\
2003 & 36 & 11 & 52 & 92 & 69 & 20 & 3 & 0 & 1,235 \\
2004 & 34 & 10 & 49 & 86 & 68 & 20 & 3 & 0 & 1,180 \\
2005 & 33 & 8 & 44 & 79 & 68 & 21 & 3 & 0 & 1,115 \\
2006 & 33 & 7 & 41 & 78 & 71 & 23 & 3 & 0 & 1,115 \\
2007 & 32 & 6 & 37 & 76 & 74 & 24 & 3 & 0 & 1,100 \\
2008 & 31 & 5 & 32 & 72 & 73 & 25 & 3 & 0 & 1,050 \\
2009 & 31 & 4 & 27 & 69 & 75 & 27 & 4 & 0 & 1,030 \\
2010 & 27 & 4 & 23 & 55 & 65 & 28 & 4 & 0 & 895 \\
2011 & 32 & 4 & 23 & 66 & 81 & 34 & 5 & 0 & 1,065 \\
\hline
\end{tabular}

A third factor contributing to less competent graduates under the influence of the overexpansion of higher education institutions is less budgetary funding of institutions from the government (Wang, 2003). In addition, resources allocated to each higher education institution are also decreasing (Huang, 2003). According to the statistics of public expenditure on education as a percentage of GDP drawn from MOE (2009), 4.39\% is allotted to all levels of education. In 2005, this was less than the average expense on education $(5.5 \%)$ of the OECD (Organization for Economic Co-operation and Development) countries. Moreover, concerning the expenditure on educational institutions as a percentage of GDP by type of institution and level of education, the ratio of difference between public higher education institutions and private ones in 2005 was $4.39 \%$ and $1.68 \%$ respectively (MOE, 2009).

Customarily, public schools with higher prestige are those allotted much more funding and equipment and facilities, while private ones rely on their income chiefly from tuition and other fees (Huang, 2003). For example, the MOE's five-year-fifty-billion funding in 2005 aiming to promote world's top-rated universities in Taiwan was allocated to twelve universities, with only two being private universities. It is apparent, therefore, most private higher education institutions have encountered "financial stringency", as a result of the predicament of low recruitment. This has caused a negative impact on teaching and learning quality in private higher education institutions because of receiving smaller share of educational resources. To solve financial problems, many private higher education institutions increase tuition and fees, with presently the tuition of private higher education institutions being 1.85 times the amount of the public ones (MOE, Department of Statistics, Taiwan, 2013). Such move has even impacted the student number in private higher education institutions, with some students even giving up study inflicted by the soaring tuition and fees.

Another problem accompanying the rising number of higher education institutions is high unemployment among graduates from higher education institutions (Wang, 2003). Under the impact of globalization, there is more intense competition among university graduates, a condition of more supply than demand. Coupled with the phenomena of global economic recession and a competitive job market, these factors have resulted in a high ratio of jobless graduates $(\mathrm{Wu}, 2011)$. According to the government statistics, the unemployment rate for individuals with a college and postgraduate degree was 5.18\% (Chang, 2012) compared to only $2.63 \%$ in 1997 (Wu, 2011). Moreover, due to shrinkage of job opportunities, many college graduates have encountered difficulty finding a suitable job that matches their learning. As $\mathrm{Wu}$ (2011) points out, in recent years, many college graduates from both developed and developing countries have undertaken jobs which do not correspond to the training they have received at schools, bringing about the problem of "over-education" or "crowding-out" (Dolado, Felgueroso, \& Jimeno, 2000; Mayhew, Deer, \& Dua, 2004; Tomlinson, 2008; Wu, 2011). Huang (2003) also points out that many an entrepreneur has perceived the graduates of higher education nowadays in the labor market as less competent, compared to those nurtured in the colleges/universities prior to the education reforms. Huang (2003) suggests that cooperation between industries and academia should also be promoted to engage students in practical training 
along with modification and improvement of curricula, institution of departments and faculty assignment.

Other perceived problems that come along with the overexpansion of higher education institutions relate to survivability of higher education institutions and their faculty because of decreasing number of enrollment of prospective students. As Chen and Chang (2010) report, some higher education institutions, particularly private ones, are confronting the problem of recruiting adequate student number to survive due to a sharp decline in student number in recent years, a situation that will not return in the near future. Many private higher education institutions are facing the problems of restructuring and likely closure (Chen \& Chang, 2010), and one problem accompanying these is that a great number of academics are confronting an awkward situation of losing jobs. To deal with these problems, the government has presented coordinated set measures by allowing institutions to recruit foreign students with quota limits. However, these foreign students still cannot compensate for the sharp decline in domestic student number in recent years. Evan though each institution is allowed to increase the number of foreign students, the language problem is another challenge faced by both foreign students and domestic college/university faculty in higher education institutions.

\subsection{2-Year Compulsory Education}

Another controversial issue having aroused the concern of the nation recently is the impending execution of 12-year compulsory education. To meet the global trend and the challenge of the 21 st century to promote international competitiveness and increase citizens' educational level in Taiwan, the Executive Yuan has since 2003, actively mapped out the scheme of 12-year compulsory education and is scheduled to put it into practice starting from academic year 2014 (MOE, 2012). The objectives of the 12-year compulsory education policy are to increase the average level of education of the citizens and the nation's competitiveness to meet the global educational trend, to promote equal opportunities in education, to relieve students' pressure from a test-driven teaching and learning mode in junior high schools, to achieve localized learning, to take care of disadvantaged students by shortening the gaps between rural and urban areas on education, and to promote comparable high quality instruction for both public and private schools (MOE, 2009).

Although the 12-year compulsory education policy has not been carried out, it has already touched off ongoing altercations among supporters and opponents, be it the general public or people in the educational circle. As stated above, the purpose of 12-year compulsory education is to popularize the nationals' education. However, many problems inherent in our education system can be likewise perceived to question the efficacy of this policy. For example, there are problems concerning the discrepancy in tuition between public schools and private schools, and unbalanced distribution of educational resources between the two types of school system. Given the tuition of private senior and vocational high schools is four times that of the public schools (MOE, 2009), yet, ironically, students in private schools do not have the same access to comprehensive teaching and learning resources and facilities as those enjoyed by public students. This seems to violate the principle of the practice of equal educational opportunities for all students (Yang et al., 2003). Moreover, teaching quality also varies in both types of schools with public schools usually having more qualified teachers than private ones. These inequalities may cast doubt on feasibility of attaining equal educational opportunity intended for 12-year compulsory education.

The same conundrum applies to the dissimilarity between rural schools and urban schools in terms of delivery of educational resources (Chen, 2007), which has an indirect impact on student recruitment for schools in rural areas. Because in urban schools students can receive education of higher quality and have more educational resources available to them, many parents would choose urban schools for their children for a promising future. As a result, many schools in rural areas have problem recruiting sufficient numbers of students. Moreover, the low fertility rate problem has even worsened the problem of low enrollment in schools in rural areas.

Another problem relating to 12-year compulsory education is the public's infatuation with beacon schools or so-called 'star' schools since they enjoy better reputation (Xu, 2007), and this has made it difficult to promote localized learning. In Taiwan, most of the beacon schools are in urban areas, and to enable their children to enter beacon schools, many parents living in rural areas transferred their children to beacon school districts instead of sending their children to less well-reputed schools in places nearby. This has caused the phenomenon of many students managing to get admitted to beacon schools. Likewise, the difficulty in recruiting sufficient student number in less reputable schools is likely to be observed after the 12-year compulsory education policy is put into practice. Moreover, the 12-year compulsory education policy also encourages junior high schools to provide assistance and guidance for students to help them understand their own aptitude and encourage underachieving students and those who are suitable for vocational education to choose the vocational track for further education. However, as one teacher at Beinan junior high school expressed, even underachievers would choose to enter beacon schools or schools with good reputation. It seems that there are currently no concrete measures presented 
to work out this problem (United Daily News, 2011)

In short, since junior high school students do not need to take the Basic Competence Test as an indicator of ability to enter senior high schools after the implementation of the 12-year compulsory education policy, without the government's and schools' intervention, intense competition among students to gain acceptance to beacon schools is sure to happen. Hence the original goodwill/intention to relieve students from burden on schoolwork by promoting the 12-year old compulsory education policy would be totally blotted out.

\section{Conclusion and Suggestions}

Taiwan's reengineering plan over the past years has gone through dramatic changes in its education system, and many phenomena are reflected in its education system such as economic and socio-political transformations, democratization, and the search for 'national identity' (Law, 2002). Under the process of educational reform, the educational system in Taiwan has developed pluralism and generalization to be its two main characteristics.

This paper presents the findings of critically analyzing three crucial concerns regarding educational reform tasks and the problems associated with these concerns. The first concern involves multilingual learning in elementary schools, which has caused cross-linguistic interference for lower grade students who are at the primary stage of L1 learning and have not yet developed L1 knowledge, but are required to study two additional languages. Although solving this problem requires further research on the effect of cross-linguistic interference on elementary students, learning three languages concurrently might deprive learners of time to develop L1 knowledge. Furthermore, learning three languages concurrently, particularly for lower-grade students, might cause learning anxiety, which might cause cognitive load and impair learning (Chen \& Chang, 2009). Therefore, multilingual learning should be delayed, particularly for lower-grade students who are still learning how to use and comprehend the complex syntactical structures and lexicon of their native spoken and written language. Multilingual learning can be conducted until students have sufficiently developed the knowledge and use of their L1. Therefore, Mandarin Chinese, the mainstream language of Taiwan, should be taught in the order of precedence.

The second problem identified in multilingual learning is that numerous elementary schools in Taiwan offer advanced English learning from Grade 1, and numerous schools allot more teaching and learning hours to English learning compared with the learning of vernacular languages (Chen, 2006). Regarding cognitive development, according to Piaget (1973), elementary students are at the stage of concrete operations (from 7 to 12 years old) and are not sufficiently mature to make logical judgments regarding their learning. If schools allocate more hours to English learning, students may develop cognitive biases and perceive the ability to use the English language as an indicator of having a higher social status than those who use their native languages. Moreover, additional and superior instructional resources are offered for English classes, but schools are not committed to providing comparable instructional quality and resources to vernacular language courses. Therefore, if a school supports English learning at the expense of native language learning, students might not prioritize learning their L1. Hence, concerned authorities (i.e., the MOE) should consider English language learning in elementary schools carefully and create related laws to prevent schools from advancing English learning. Moreover, schools should not favor English learning at the expense of native-language learning; instead, they should encourage students to undertake the learning of local dialects seriously.

The third problem derived from multilingual learning is the unbalanced instruction of vernacular languages. Unlike the Minnanese language, which is the most frequently used language in Taiwanese society, Hakka and aboriginal languages are not promoted for instruction because they are deemed less practical. In addition, learning aboriginal languages is not supported by aboriginal families or the respective communities (Law, 2002; Yang, 2002). The purpose of learning vernacular languages is to maintain and appreciate the value of ethnic languages and cultures to build an integrated, socially cohesive multicultural society. If society as a whole does not share a common consensus, other local languages, particularly the less prestigious and less commonly spoken aboriginal languages, would eventually disappear. In addition, the speakers of regional dialects would be distinctly disadvantaged because culturally specific information would vanish along with their languages. Therefore, a reeducation of Taiwanese society concerning aboriginal languages, combined with the community support of aboriginal parents in maintaining local dialects, can facilitate the successful implementation of local language policies (Greymorning, 1999; Stiles, 1997).

To maintain local dialects, schools in Taiwan should offer teachers opportunities to learn Hakka and aboriginal languages by establishing teacher education programs or encouraging instructors to participate in local dialect learning programs. Thus, teachers can have an opportunity to understand and appreciate the two regional dialects and the respective cultures, and preserve a more positive attitude toward the two regional dialects while helping students choose which vernacular languages to learn. Moreover, schools and teachers should collaborate with 
aboriginal parents and communities to conduct aboriginal language and cultural activities to help aboriginal people understand the importance of maintaining their languages and cultures.

The final problem concerning multilingual learning in elementary schools is that vernacular languages lack a well-developed and unified writing or spelling system. Because schools do not emphasize the recognition of written vernacular languages (Chen, 2006), learners encounter substantial difficulties in developing literacy. A writing system is developed to preserve a local language. If learners cannot recognize the writing system of a specific regional language, the language would not be adequately preserved. Moreover, a unified spelling system should be developed to establish a cognitive connection with vernacular language learning to facilitate effective learning.

The second problem discussed in this paper concerns the overexpansion of higher education. The deregulation of educational policy has generated the unhindered access of secondary school graduates to higher education, which has subsequently produced numerous problems, primarily regarding the degradation of the overall quality of education. Certain factors generating this degradation of higher education were identified. The first factor is the curriculum of multilevel classes not being adjusted. The phenomenon of mixed-level classrooms indicates that at least two student cohorts, the competent and less competent ones, may not be learning in the classroom. To solve this problem, adjusting curricula to fit various students is necessary. Moreover, implementing a placement method commonly used to group students based on ability levels may effectively facilitate the management of multilevel classes.

The second factor contributing to low-quality higher education is the non-interfering attitude of the involved institutions and instructors toward students and schoolwork because of the decrease in the number of students, a critical factor that is closely associated with the survival of a school. This implies that the overall educational quality of the current student generation is declining rather than improving after the expansion of higher education institutions. Such institutions and their teachers should not let quantity (i.e., the number of students) influence the quality of teaching. As Hénard and Roseveare (2012, p. 7) argued, high-quality teaching (e.g., the effective design of curricula and course content, and the effective assessment of learning outcomes) is directly related to the learning outcomes of students. Institutions should attach more importance to the teaching quality of instructors by establishing evaluation indices to ensure high-quality instruction. Therefore, only by emphasizing high-quality teaching can an institution survive and maintain a favorable recruitment level.

The third factor that causes the degradation of higher education institutions concerns the unequal allocation of educational funds, with public higher education institutions conventionally obtaining superior educational resources because they receive generous government subsidies. Although more private higher education institutions were established after the expansion of higher educational institutions, superior research, instructional facilities, and educational subsidies are still limited to public higher education institutions (Chen \& Chang, 2010). This indicates that most of the students attending higher education institutions in Taiwan are at a disadvantage because they cannot receive adequate training or easy access to learning resources. Furthermore, students at private higher education institutions must pay higher tuition fees but are unable to receive a comprehensive education; consequently, they receive a diploma that is possibly less respectable than a diploma from a public institution (Chen \& Chang, 2010). Therefore, the government should be held accountable for the low educational quality in private higher education institutions in Taiwan. To solve this problem, the government should reject traditional approaches by impartially and evenly distributing educational resources to each institution, be it public or private, to provide equal educational opportunities for each student.

Another problem associated with the increasing number of higher education institutions is the high unemployment rate of graduates, most of whom are less competent graduates. Graduates often cannot find jobs that require the knowledge they learned in these institutions because the institutions did not offer them training in the skills that could be applied to jobs. To solve this problem, higher educational institutions should understand the skills or competencies various industries demand and the type and level of expertise a graduate should possess to be competitive in the job market by reexamining curricula. Moreover, cooperation between institutions and industries can be established to connect learning to job-related skills and help students acquire job-specific competencies demanded by industries. As Hénard and Roseveare (2012) argued,

Tighter connections with working life through different academic projects provide authentic opportunities to learn both generic and professional competencies as well as to build networks and pathways for employment after graduation... Learning rooted in working life could help institutions to interpret and respond pedagogically to the challenges of this environment. (pp. 8-9)

Other problems generated by the overexpansion of higher education institutions are the survivability of higher 
education institutions, particularly private ones, and the resultant unemployment of graduates, a predicament confronted by school faculty. Although the government allows institutions to recruit foreign students to compensate for insufficient student enrollment, these foreign students still cannot offset the declining number of students caused by the low fertility rate in Taiwan. Therefore, to help private higher education institutions survive, the government should take appropriate remedial measures and present workable solutions.

One possible solution involves the MOE limiting student enrollment in pubic universities. Most prospective students, if possible, consider public universities to be their priority when choosing schools. Moreover, the low fertility rate has caused intense competition for student recruitment to develop among higher education institutions, and numerous public universities exploit their superior reputation to attract additional students. The result is that private higher education institutions experience difficulties in recruiting a sufficient number of students. Intrinsically, public universities are research-based universities; hence, the majority of the students they recruit should be postgraduate students. In other words, universities can increase the number of postgraduate students but scale down the number of university students to allow private higher institutions to recruit additional students. A second solution entails the government coaching private universities with insufficient student enrollment to help them transform into community organizations (e.g., community colleges and adult schools) that offer degrees, and consequently increase the number of students by recruiting various students, including adult students with diverse backgrounds and elderly people.

The third problem involves the forthcoming implementation of 12-year compulsory education. Based on the concept of equalized and popularized education, the Taiwanese government has planned to execute the 12-year compulsory education policy in the forthcoming academic year. However, executing this policy may be easier than attaining the intended goal, which is oversimplified. It is much more intricate than the government expects, because of several unjust phenomena and stereotyped perceptions existing in the Taiwanese educational system.

As mentioned, large differences exist between public and private schools including dissimilar standards regarding tuition, unequal access to school facilities and resources, and the quality of instruction. A similar situation between urban schools and rural schools was also observed regarding the distribution of educational resources and the quality of instruction. The discrepancies between public and private schools and between urban and rural schools, combined with the low fertility rate problem, imply that after 12-year compulsory education is implemented in the coming year, substantially lower enrollment rates in private and rural schools will occur. To solve this problem, the Taiwanese government must decrease the number of dissimilarities between public and private schools and between urban and rural schools by increasing educational funds and strengthening educational resources for private and rural schools. In brief, equalized education cannot be achieved if the government cannot efficiently manage this problem by reducing the differences in the distribution of educational funds and resources between public and private schools and between urban and rural schools.

Another inherent problem concerning the 12-year compulsory education policy is that the public prefers beacon schools, where many parents have sent their children. This preference has promoted intense competition among students trying to gain acceptance to beacon schools, consequently increasing the difficulty of localized learning. Moreover, although some students are more suitable for vocational education, without the assistance and guidance of schools, they might attend general high schools or possibly enroll in beacon schools because of the popularity of beacon schools. Consequently, an increased number of junior high school students may attempt to enroll in beacon schools after the implementation of the 12-year compulsory education policy.

Beacon schools are a form of elite education that equips students with higher academic qualifications. However, not every student is suitable for attending beacon schools. Currently, no concrete measures have been implemented to solve the problem concerning the existence or abolishment of beacon schools. At the minimum, junior high schools should help parents understand their children's aptitude and characteristics to decide which type of school their children should attend. Moreover, schools should provide students with guidance and assistance to help them choose the most suitable type of school.

The recognized problems of the three important education reform tasks discussed in this article are considered to be the key challenges in the Taiwan's education system. However, to render a more comprehensive interpretation of the challenges involved in the three important problems requires further in-depth exploration of these perceived problems brought out in this paper.

\section{References}

Berman, E. M. (1996). The politics of American education and struggle for cultural dominance. Melbourne Studies in Education, 37(1), 21-45. http://dx.doi.org/10.1080/17508489609556277 
Bickerton, D. (1981). Roots of language. Ann Arbor, MI: Karoma Publishers.

Brown, H. D. (2000). Principles of language learning and teaching. White Plains, NY: Longman.

Chang, F-Y. (2012, September 30). Looking at generation justice from high unemployment and low pay of the youth. New Century Think Tank, 59, 91-93.

Chen, D.-S., \& Chang, M.-K. (2010). Higher education in Taiwan: The crisis of rapid expansion. Universities in Crisis, Blog of the International Sociological Association (ISA). Retrieved September 9, 2013, from http://www.isa-sociology.org/universities-in-crisis/?p=417

Chen, I.-J., \& Chang, C.-C. (2009). Cognitive load theory: An empirical study of anxiety and task performance in language learning. Electronic Journal of Research in Educational Psychology, 7(2), 729-746. Retrieved from http://www.investigacion-psicopedagogica.com/revista/articulos/18/english/Art_18_348.pdf

Chen, J. J. (2002). Reforming textbooks, reshaping school knowledge: Taiwan's textbook deregulation in the 1990s. Pedagogy, Culture and Society, 10(1), 39-72. http://dx.doi.org/10.1080/14681360200200129

Chen, S. C. (2004). Linguistic vitality in Taiwan: A sociolinguistic study. A NSC Study Report.

Chen, S. C. (2006). Simultaneous promotion of indigenisation and internationalisation: New language-in-education policy in Taiwan. Language and Education, 20(4), 322-337. http://dx.doi.org/10.2167/le632.0

Chen, Q. X. (2007). The collection of relative research of the 12-year compulsory education. Journal of Education Research, 24(2), 85-94.

Clark, C. M., \& Peterson, P. L. (1986). Teachers' thought processes. In M. C. Wittrock (Ed.), Handbook of research on teaching (pp. 255-296). New York: Macmillan.

Directorate-general of budget, accounting, and statistics. (2007). Statistical Yearbook of the Republic of China 2007.

Dolado, J. J., Felgueroso, F., \& Jimeno, J. F. (2000). Youth labour markets in Spain: Education training, and crowding-out. European Economic Review, 44, 943-956. http://dx.doi.org/10.1016/S0014-2921(99)00050-1

E, C. C. (2003). A survey of Taiwanese attitudes toward the current language education policies and their solidarity with the ethnolinguistic groups. National Kaohsiung Normal University, Department of English, Kaohsiung, Taiwan.

Greymorning, S. (1999). Running the gauntlet of an indigenous language program. Papers presented at the Annual Stabilizing Indigenous Language Symposium, 5th, Louisville, KY.

Hénard, F., \& Roseveare, D. (2012). Fostering quality teaching in higher education: Policies and Practices. An IMHE Guide for Higher Education Institutions.

Hsiau, A. C. (1997). Language ideology in Taiwan: The KMT's language policy, the Tai-Yu language movement, and ethnic politics. Journal of Multilingual and Multicultural Development, 18(4), 302-315. http://dx.doi.org/10.1080/01434639708666322

Hsu, M. J. (2004). A review of Taiwan's educational reforms. Taiwan Development Perspectives, 111-120. Retrieved August 10, 2013, from http://old.npf.org.tw/monograph/books/TDP2004.pdf

Huang, J. T. (2003). The Current development and challenges of higher education in Taiwan. A Speech by Dr. Jong-Tsun Huang Minister of Education, October 13, 2003. Retrieved from http://www.edu.tw/EDU_WEB/EDU_MGT/BICER/EDUANDY001/english/e031018.htm?open

Jiang, W. Y. (1995). Probing into the current situation of the vernacular language teaching in Taiwan. World Chinese Language, 25, 59-65.

Kagan, D. M. (1992). Implications of research on teacher belief. Educational Psychologist, 27, 65-90. http://dx.doi.org/10.1207/s15326985ep2701_6

Kao, Y. L. (2001). The teaching of Taiwanese of the 9-Year Joint Plan: A study of the difference between ideals and practice (Unpublished Master's thesis). National Taipei Normal University, Graduate School of Curriculum and Instruction, Taipei, Taiwan.

Klaus, D. (2003). The use of indigenous languages in early basic education in Papua New Guinea: A model for elsewhere? Language and Education, 17(2), 105-111. http://dx.doi.org/10.1080/09500780308666842

Law, W. W. (1995). The role of the State in higher education reform: Mainland China and Taiwan. Comparative Education Reviews, 39(3), 322-355. http://dx.doi.org/10.1086/447326 
Law, W. W. (2002). Education reform in Taiwan: A search for a 'national' identity through democratization and Taiwanisation. Compare, 32(1), 61-81. http://dx.doi.org/10.1080/03057920120116535

Lenneberg, E. H. (1967). The biological foundations of language. New York: John Wiley \& Sons.

Lin, C. H. (2007). Education expansion, educational inequality, and income inequality: Evidence from Taiwan, 1976-2003. Social Indicators Research, 80(3), 601-615. http://dx.doi.org/10.1007/s11205-006-0009-8

Lin, Y. W. (2002). Course programme and finding of primary pupils learning POJ. 2002. Tai-oan-lo-ma-ji kau-hak kap gian-kiu kok-che hak-sut gian-tho-hoe.

Liu, F. R. (1998). A discussion of the planning and implementation of mother tongue teaching. Guidance of Elementary Education, 37, 28-30.

Liu, Y. L., \& Wang, D. M. (2004). An analysis of the total fertility rate in Taiwan area: Variation of completed fertility rate and tempo of fertility. Proceedings of the Review of Policies and Perspectives of Population, Family, and Nationals' Health. National Chengchi University, Taipei, Taiwan.

Mayhew, K., Deer, C., \& Dua, M. (2004). The move to mass higher education in the UK: Many questions and some answers. Oxford Review of Education, 30(1), 65-82. http://dx.doi.org/10.1080/0305498042000190069

Ministry of Education, Taiwan. (2009). Education in Taiwan. Retrieved March 18, 2010, from http://english.moe.gov.tw/ct.asp?xItem $=11701 \&$ ctNode $=814 \& \mathrm{mp}=1$

Ministry of Education, Department of Statistics, Taiwan. (2012). Statistics on the number of junior colleges, colleges and universities. Retrieved November 12, 2012, from http://www.edu.tw/files/site_content/B0013/overview03.xls

Ministry of Education, Department of Statistics, Taiwan. (2013). Important education statistics information. Retrieved July 29, 2013, from http://www.edu.tw/pages/detail.aspx?Node=4076\&Page=20047\&Index=5\&WID=31d75a44-efff-4c44-a075 $-15 \mathrm{a} 9 \mathrm{eb} 7 \mathrm{aecdf}$

Ministry of Education, Department of Statistics, Taiwan. (2012). Statistics on the number of college/university freshmen and the enrollment rate. Retrieved November 28, 2012, from http://www.edu.tw/files/site_content/B0013/overview09.xls

Ministry of the Interior, Department of Statistics, Taiwan. (2012). Total fertility rate for women of child bearing age. Retrieved June 20, 2007, from http://sowf.moi.gov.tw/stat/year/y02-04.xls

Mok, K. H. (2000). Reflecting globalization effects on local policy: Higher education reform in Taiwan. Education Policy, 15, 637-660. http://dx.doi.org/10.1080/02680930010000236

Nixon, J. (1996). Professional identity and the restructuring of higher education. Studies in Higher Education, 21(1), 5-16. http://dx.doi.org/10.1080/03075079612331381417

Parry, G. (1995). England, Wales and Northern Ireland. In P. Davies (Ed.), Adults in higher education: International perspectives on access and participation (pp. 102-133). London: Jessica Kingsley.

Piaget, J. (1973). Main trends in psychology. London: George Allen \& Unwin.

Population Reference Bureau. (2007). 2006 World Population Data Sheet. Retrieved October 19, 2013, from http://www.prb.org/pdf06/06worlddatasheet.pdf

Qian, Q. H. (1996). A class between familiarity and unfamiliarity: Analysis of elementary indigenous language teaching (Unpublished master's thesis). National Taipei Normal University, Graduate School of Curriculum and Instruction, Taipei, Taiwan.

Romaine, S. (1995). Bilingualism (2nd ed.). Oxford: Blackwell Publishers.

Schmidt, A. (1990). Loss of Australia's aboriginal language heritage. Canberra: Aboriginal Studies.

Stiles, D. B. (1997). Four successful indigenous language programs. In J. A. Reyhner (Ed.), Teaching indigenous languages (pp. 248-262). Flagstaff, AZ: Northern Arizona University.

Tai, Z. (2000). The interference of Southern Min in Lugang students' English pronunciation (Unpublished master's thesis). National Kaohsiung Normal University, Department of English, Kaohsiung, Taiwan.

The Epochtimes (2007, July 7). The drop-out rate is much lower than the enrollment rate: Thirty percent less of drop-out rate and nil of four schools. Retrieved July 7, 2007, from http://www.epochtimes.com/b5/7/7/6/n1765573.htm 
Throw, M. (1974). The expansion and transformation of higher education. International Review of Education, 18, 61-68. Berkeley, CA: University of California, Berkeley. http://dx.doi.org/10.1007/BF01450272

Tomlinson, M. (2008). 'The degree is not enough': Students' perceptions of the role of higher education credentials for graduate work and employability. British Journal of Sociology of Education, 29(1), 49-61. http://dx.doi.org/10.1080/01425690701737457

Tsai, S. L., \& Shavit, Y. (2003). Higher education in Taiwan: Expansion and inequality of educational opportunity. Paper presented at the International Sociology Association RC28 Research Committee on Social Stratification and Mobility's New York Meeting, August 22-24.

Tu, C.-S. (2007). Taiwan's educational reform and the future of Taiwan. Invited speech presented at London School of Economics and Political Science. Retrieved from http://www.lse.ac.uk/collections/taiwanProgramme/TaiwanEducationalReform_English.pdf

United Daily News. (2011, November 19). 12-year compulsory education: It is hard to break the myth of star schools. Retrieved October 3, 2013, from http://mag.udn.com/mag/edu/storypage.jsp?f_ART_ID=348903

Villegas, A. (1992). The competence needed by beginning teachers in a multicultural society. Paper presented at the annual meeting of the American Association of Colleges of Teacher Education, San Antonio, TX.

Wang, C. T. (2005). Trends and issues in pluralistic educational reform. Journal of Educational Research and Development, 1(2), 1-17.

Wang, R. J. (2003). From elitism to mass higher education in Taiwan: The problems faced. Higher Education, 46(3), 261-287. http://dx.doi.org/10.1023/A:1025320312531

Wu, C.-C. (2011). High graduate unemployment rate and Taiwanese undergraduate education. International Journal of Educational Development, 31, 303-310. http://dx.doi.org/10.1016/j.ijedudev.2010.06.010

Wu, T.-Y. (2011). Learning English in Taiwan's Elementary Schools. Journal of Futures Studies, 16(2), 35-46.

Xu, M. Z. (2007). 12-year compulsory education: Stop, listen and watch. Resource document: NPF Commentary, National Policy Foundation. Retrieved June 20, 2007, from http://www.npf.tw/particle-2254-1.html

Yang, L. Z. (2002). A case study of Minnanese language teaching of the 9-Year Joint Plan. Unpublished master's thesis, National Taipei Normal University, Graduate School of Curriculum and Instruction, Taipei, Taiwan.

Yang, S. K. (2000). Teacher education for the 21st century. Paper presented at 2000 annual meeting of the Comparative and International Education Society, San Antonio.

Yang, S. K. (2001). Dilemmas of education reform in Taiwan: Internationalization or localization? Paper presented at the 2001 annual meeting of the Comparative and International Education Society, Washington D.C., U.S.A.

Yang, S. W., Shi, M. F., Huang, Q. F., Huang, W. Z., Xu, Z. Y., \& Chen, W. P. (2003). A study of the model of processing the promotion of the 12-year compulsory education. An Entrusted Project Report of Ministry of Education.

\section{Notes}

Note 1 . The total fertility rate (TFR): The average number of children a woman would have assuming that current age-specific birth rates remain constant throughout her childbearing years, usually considered to be ages 15 to 49 .

Note 2. Projected population is based upon reasonable assumptions on the future course of fertility, mortality, and migration. Projections are based upon official country projections, series issued by the UN or the U.S. Census Bureau, or PRB projections.

\section{Copyrights}

Copyright for this article is retained by the author(s), with first publication rights granted to the journal.

This is an open-access article distributed under the terms and conditions of the Creative Commons Attribution license (http://creativecommons.org/licenses/by/3.0/). 